\title{
O ENSINO DA METODOLOGIA ASSISTENCIAL DE ENFERMAGEM DEPARTAMENTO DE ENFERMAGEM — UFSC
}

\author{
Lidvina Horr* \\ Lucia H. Takase Gonçalve.s* \\ Rosita Saupe*
}

HORR, L.; GONÇALVES, L.H.T.; SAUPE, R. $O$ ensino da metodologia assistencial de enfermagem. Departamento de Enfermagem - UFSC. Rev. Esc. Enf. USP, São Paulo, 21 (11\%/especial) : 10-54, 1987.

$O$ presente estudo teve como objetivo identificar a opiniäo e a experiência dos enfermeiros (docentes $e$ assistenciais) da UFSC relativos $\dot{a}$ Teoria e processo de enfermagem de Horta e comparar a opiniáo atual dos docentes sobre o ensino do processo de enfermagem com a de 1979. Os dados foram colhidos por meio de questionários. Evidenciou-se que a Teoria das necessidades humanas básicas de Horta $\dot{e}$ a mais utilizada no atual ensino e prática dos enfermeiros da UFSC.

\section{1 - INTRODUÇÃO}

Wanda de Aguiar Horta, a enfermeira e mestra que indiscutivelmente marcou época na enfermagem brasileira, expandindo seus horizontes humanisticos, científicos, sociais e técnicos. É sempre com uma grande dose de emoção que a relembramos.

Nós, suas ex-alunas, que tivemos o privilégio do convivio com sua pessoa tão gente, que discutimos, discordamos, mas acabamos nos convencendo, passando a defender suas idéias, hoje, ao participarmos deste evento em sua homenagem, temos a sensação de que parte significativa de um objetivo foi atingido.

Explicamos melhor, reconhecendo que durante estes anos em que temos trabalhado na implantação de uma metodologia de enfermagem, tendo como fundamentação a teoria e o processo de Horta, tanto ao nivel do ensino como da assistência, tivemos, mais do que freqüentemente a sensação, nem sempre expressa, de que estávamos "impondo" ou "forçando" algo que não sobreviveria à nossa ausência. Hoje, a oportunidade de participarmos da "Semana Wanda de Aguiar Horta", possibilitou-nos reconsiderar estas percepções tão subjetivas.

Confessamos nosso temor ao elaborarmos os instrumentos para coletar os dados apresentados neste relato. Temíamos que os respondentes não desenvolvessem os questionários, o que seria interpretado como descaso, ou que opinassem muito negativamente, o que anularia nosso entusiasmo em divulgar os resultados. Todavia, a presteza com que atenderam a nossa solicitação, aliada aos resultados tão animadores, levam-nos

* Professora do Departamento de Enfermagem da UFSC. 
a acreditar que Wanda de Aguiar Horta é um marco de referência do maior significado para os enfermeiros de Santa Catarina.

A influência de Horta na enfermagem catarinense faz-se sentir desde o inicio do funcionamento do curso de graduação em enfermagem da Uni. versidade Federal de Santa Catarina (UFSC), que ocorreu em 1969.

Desde essa época suas idéias têm estado permeando nosso ensino, nossa prática e nossas incursões pelos caminhos da investigação; seja através de cursos ministrados aos docentes e alunos; seja mantendo uma assessoria alimentada por correspondência pessoal com os professores; seja através das tentativas de incluir, inicialmente, o processo como método científico de trabalho e posteriormente, graças a um melhor entendimento, uma metodologia assistencial no desenvolvimento das disciplinas.

A área de Enfermagem Fundamental, seguida de Administração Aplicada à Enfermagem, foram as primeiras a organizarem seu ensino orientando-o pela teoria e processo de Horta. Esta tendência foi se expandindo para as demais áreas, com melhor receptividade em algumas, como Enfermagem Psiquiátrica e algumas resistências em outras. Atualmente, podemos afirmar que todas as áreas do ensino da enfermagem na UFSC são influenciadas direta ou indiretamente pelas idéias propostas por Horta.

Em 1976, com a criação da pós-graduação em enfermagem na UFSC e funcionamento do curso de mestrado, renova-se a influência de Horta, que passa a atuar neste curso como professora convidada. Nesta época suas idéias já estavam mais elaboradas e a própria experimentação havia levado a autora a reformulações que deram maior consistência à possibilidade de viabilizar na prática a implantação de uma metodologia assistencial.

Outro marco significativo que vamos detectar ao acompanhar a influência de Horta na enfermagem preconizada pelos enfermeiros da UFSC, refere-se à implantação do Hospital Universitário, primeiro a instituir uma metodologia assistencial no Estado, no ano de 1980 . O modelo que vem sendo utilizado estabelece o atendimento de todos os pacientes através de:

- levantamento de problemas iniciais que alteram o atendimento das necessidades humanas através do Histórico de enfermagem;

- prescrição diária de cuidados que atendam as necessidades afetadas, procurando-se solução ou atenuação dos problemas detectados;

- evolução diária com o objetivo de registrar problemas solucionados e detectar os novos que venham a ocorrer.

Esta metodologia é entendida como a aplicação do processo orientado pelos conceitos, pressuposições e princípios da teoria das necessidades humanas básicas. 
As autoras acreditam que a influência de Horta na enfermagem catarinense representa uma parcela a nivel nacional.

Esta afirmação pode ser confirmada consultando-se os periódicos nacionais de enfer'magem que vêm registrando as tendências da profissão no país.

Para ilustrar, apresentamos os resultados de uma análise preliminar da revista "Enfermagem em Novas Dimensões". Este periódico lançou no período de 1975 a 1979, 5 volumes com um total de 27 exemplares, já que o último volume não completou os 6 exemplares, como os demais. Neste acervo encontramos 238 artigos publicados e destes temos que 42 relacionam-se de alguma maneira a teoria e/ou processo de Horta. Dos 42 artigos referidos, 10 foram escritos por Horta e os demais .por outros autores. Aqueles produzidos pela autora da Teoria das Necessidades Humanas Básicas, tratam da explicitação da mesma, bem como de sua operacionalização através do Processo de Enfermagem. Os demais autores, em 24 artigos, desenvolvem conceitos relativos à teoria ou processo como: abordagem de uma das necessidades humanas; passos do processo de enfermagem; conceito de cuidado e assistência. Os 8 artigos restantes representam relatos de experiências de ensino ou investigação relacionados principalmente a parte ou partes dos componentes do hexágono de Horta.

Outra abordagem que pode ser utilizada para detectar a influência de Horta na produção técnico-científica dos enfermeiros brasileiros é verificar o uso da terminologia que caracteriza seus escritos permeando-os de outros autores ao relatarem experiências de ensino ou de implementação do processo/teoria. Vejamos alguns exemplos.

No relato de uma experiência de implantação da prescrição de enfermagem em um hospital particular, cujos resultados foram considerados eficientes por suas idealizadoras, são definidos termos como "evolução de enfermagem" e "prescrição de enfermagem". No mesmo relato as autoras recomendam "que se planejem pesquisas visando determinar bases para a introdução sistemática do método em todos os serviços de enfermagem" 2 .

Ao descreverem a utilização de um modelo de histórico e plano de assistência de enfermagem à família, NOGUEIRA et alli ${ }^{3}$ salientam que a "assistência se fundamenta em necessidades básicas universais do ser humano que variam com o estado de saúde e o grau de dependência da família em relação à execução dessas atividades".

Numa experiência de ensino de assistência de enfermagem ao paciente, durante $o$ período trans-operatório, CASTELLANOS et alli ${ }^{1}$ enfatizam a importância do planejamento do cuidado de enfermagem "partindo das necessidades humanas básicas afetadas do cliente".

SAUPE E HORR ${ }^{4}$ ao descreverem o método de assistência de enfermagem do Hospital Universitário da UFSC registram que o mesmo "está fundamentado na teoria das necessidades humanas básicas, no processo de 
enfermagem, idealizado por Horta e no sistema de prontuário orientado para o problema, preconizado por Weed".

Em outro relato de experiência do ensino de graduação quanto à assistência de enfermagem ao adulto na zona rural, a autora registra que utilizou "conıo instrumento de trabalho, o histórico de enfernagem de Horta (1979), adaptado às características do campo" 5 .

Os dados que estão apresentados e analisados neste trabalho representam como que uma avaliação efetivada através da opinião dos enfermeiros da UFSC (docentes e assistenciais), da influência de Horta numa parte significativa da enfermagem catarinense.

\section{2 - OBJETTVOS}

2.1 - Identificar a opinião e a experiência dos docentes e enfermeiros da UFSC relativas à teoria e processo de enfermagem de Horta e de outras teoristas.

2.2 - Replicar o levantamento de opinião dos docentes de enfermagem da UFSC, feito em 1979, sobre o ensino do processo de enfermagem junto aos atuais docentes de enfermagem da UFSC para comparação dos resultados.

\section{3 - MATERIAL E MÉTODOS}

Para descrever o ensino da metodologia assistencial de enfermagem na UFSC, optou-se por uma pesquisa que se baseasse nos dados de opinião e experiências sobre o tema, oriundos da mesma Universidade. Incluiu-se enfermeiros do Hospital Universitário pois se tinha conhecimento antecipado do elevado número de egressos do Curso de Enfermagem da UFSC, aptos para opinar sobre o ensino que receberam.

A população, durante o período de coleta de dados, constituia-se de 60 docentes enfermeiros do Departamento de Enfermagem e de Saúde Pública e 53 enfermeiros lotados no Hospital Universitário.

Os dados foram coletados por meio de dois tipos de questionário: o enviado aos docentes foi o mesmo utilizado em 1979 onde se perguntava a respeito da necessidade do ensino do processo de enfermagem e dos fatores que interferem neste ensino. À este questionário foi acrescida uma $2^{\mathrm{a}}$ parte composta de questões sobre a influência de Horta na prática profissional de cada respondente, seu ponto de vista quanto aos aspectos fortes e aqueles que precisam ser melhor elaborados e definidos quanto a teoria e processo de enfermagem de Horta, e sobre conhecimento e opinião de outras teorias de enfermagem; já, o questionário enviado aos enfermeiros continha questões relativas a aprendizagem, experiência e praticabilidade da teoria e processo de enfermagem de Horta e o nível de conhecimento teórico e prático dos mesmos em relação às teorias de enfermagem mais divulgadas em nosso meio. 
A coleta de dados realizou-se de 30-07 a 05-08-86, obtendo-se uma amostra considerável de $81,4 \%$. Os dados foram classificados, resumidos e apresentados, utilizando-se a estatística descritiva.

\section{4 - RESULTADOS}

\section{1 - Resultados referentes ao corpo docente}

Dos 60 docentes, $49(81,6 \%)$ responderam o questionário, dos quais $33(67,3 \%)$ são graduados de 5 a 14 anos e os demais $(32,7 \%)$, de 15 a 30 anos.

Para a maioria dos professores $(61,3 \%)$ a aprendizagem do processo de enfermagem ocorreu durante o Curso de Graduação. Por outro lado, $37(75,5 \%)$ freqüentaram curses de atualização sobre o tema e 13 $(26,5 \%)$ tiveram oportunidade de implantar ou participar da implantação do processo ou parte dele, em Instituições de Saúde.

Os dados parecem demonstrar que a partir da maior divulgação do processo de enfermagem por Horta, o corpo docente do Departamento de Enfermagem da UFSC tem manifestado considerável interesse pelo ensino e aprendizagem da reterida metodologia.

A tabela 1 apresenta a opinião dos docentes quanto à teoria "mais adequada" para orientar o ensino de graduação. Os dados parecem revelar que várias teorias devam nortear o ensino e não apenas uma. Entre-

TABELA 1

OPINIAO DOS ENFERMEIROS DOCENTES DA UFSC QUANTO A TEORIA MAIS ADEQUADA PARA ORIENTAR O ENSINO DO CURSO DE GRADUAÇAO EM ENFERMAGEM. (FLORIANOPOLIS, AGOSTO, 1986).

\begin{tabular}{|c|c|c|}
\hline \multirow[b]{2}{*}{ Autoras } & \multicolumn{2}{|c|}{ Frequincia } \\
\hline & Ne & $\%$ \\
\hline $\begin{array}{l}\text { Horta } \\
\text { Horta, Oren } \\
\text { Horta, Oren, King } \\
\text { Horta, King } \\
\text { Horta, Oren, King, Orlando } \\
\text { Horta, Oren, King, Rogers } \\
\text { Horta, Oren, Rofers } \\
\text { Horta, Oren, Abdellah, Henderson } \\
\text { Horta, Abdellah, Lygia Paim } \\
\text { Oren, Orlando, Abdellah } \\
\text { Oren, Rogers, Leininger } \\
\text { King } \\
\text { King, Robers, Roy } \\
\text { Rogers } \\
\text { Não Assinalaram }\end{array}$ & $\begin{array}{l}14 \\
06 \\
06 \\
04 \\
02 \\
01 \\
01 \\
01 \\
01 \\
01 \\
01 \\
02 \\
01 \\
01 \\
07\end{array}$ & $\begin{array}{r}28,6 \\
12,2 \\
12,2 \\
8,2 \\
4,1 \\
2,0 \\
2,0 \\
2,0 \\
2,0 \\
2,0 \\
2,0 \\
4,1 \\
2,0 \\
2,0 \\
14,3\end{array}$ \\
\hline Total & 49 & 100,0 \\
\hline
\end{tabular}


tanto, ao se considerar, isoladamente, a freqüência com que cada autor foi indicado, observa-se nítida preferência por Horta $(73,5 \%)$, seguida por Oren $(38,8 \%)$, King $(32,6 \%)$ e Rogers $(10,2 \%)$.

A teoria e processo de enfermagem, atualmente, mais utilizados no ensino de graduação da UFSC, segundo o depoimento do corpo docente, é a teoria das necessidades humanas básicas e processo de enfermagem de Horta $(61,2 \%)$, seguida por Horta associada a outra(s) teorista (s) $(8,2 \%)$, atingindo o total de $69,4 \%$. Foram indicados ainda: Abdellah $(4,1 \%)$ e Oren $(2,0 \%)$.

Embora, na opinião do corpo docente, várias teorias devam orientar o ensino de graduação em enfermagem da UFSC, o que ficou demonstrado na tabela 1, a teoria das necessidades humanas básicas e o processo de enfermagem de Horta é a mais utilizada $(69,4 \%)$ no atual ensino de graduação.

O corpo docente, no seu atual estágio de compreensão e utilização de uma metodologia assistencial de enfermagem, analisando a influência recebida por Horta, declarou que esta influenciou em: grande proporção, $61,3 \%$; média proporção, $24,5 \%$ e pequena proporção $6,1 \%$. Três $(6,1 \%)$ afirmaram não terem sofrido nenhuma influência e um dos professores não manifestou a sua opinião a respeito. $O$ número de professores que sofreram de média a grande influência, somam $42(85,8 \%)$.

Os professores tiveram, também, a oportunidade de expressar a contribuição de Horta na sua prática profissional, ou seja: "no que ensinam"; "na assistência que prestam" e "nos trabalhos técnico-científicos que produzem". Apenas $42(85,7 \%)$ dos docentes opinaram a respeito, assinalando uma ou mais alternativas, obtendo-se um total de 84 respostas. Para $35(83,3 \%)$, dos 42 respondentes, a maior contribuição de Horta está relacionada com o que o professor ensina. $E$, também, relevante, para 31 (73,8\%) professores, a contribuição da autora, na assistência que os mesmos prestam. Os trabalhos técnico-científicos produzidos alcançaram um percentual de $42,8 \%$. Estes resultados reforçam os depoimentos já anteriormente colocados, quais sejam: a teoria de Horta foi considerada a mais adequada para direcionar o ensino; é a mais utilizada no atual ensino de graduação e a maioria $(85,8 \%)$ do corpo docente admitiu ter sido influenciada em média e grande proporção pela autora.

Os professores foram solicitados a opinar sobre os pontos fortes da teoria e processo de Horta. Somente $16(32,6 \%)$ focalizaram os dois aspectos, ou seja teoria e processo, $13(26,5 \%)$ relacionaram, apenas, aspectos da teoria, $12(24,5 \%)$ fizeram referência ao processo e 08 $(16,4 \%)$ não opinaram.

Os pontos fortes da teoria indicados pelos 29 docentes, podem ser observados na tabela 2 . 
TA B E L 2

PONTOS FORTES DA TEORIA DE HORTA, SEGUNDO A OPINIAO DOS ENFERMEIROS DOCENTES DA UFSC. (FLORIANOPOLIS, AGOSTO DE 1986).

\begin{tabular}{|c|c|c|}
\hline \multirow[b]{2}{*}{ Pontos Fortes } & \multicolumn{2}{|c|}{ Frequincia } \\
\hline & $\mathbf{N}^{9}$ & $\%$ \\
\hline Necessidades humanas básicas & 17 & 58,6 \\
\hline $\begin{array}{l}\text { Conceitos (holismo, humanismo, } \\
\text { assistência individualizada) }\end{array}$ & 10 & 34,6 \\
\hline Toda teoria & 01 & 3,4 \\
\hline Por ser uma teoria brasileira & 01 & 3,4 \\
\hline Total & 29 & 100,0 \\
\hline
\end{tabular}

A tabela 3, apresenta os pontos fortes do processo de Horta, tendo as fases do mesmo atingido o percentual mais elevado.

T A B ELA 3

PONTOS DO PROCESSO DE ENFERMAGEM DE HORTA, INDICADOS COMO FORTES, PELOS ENFERMEIROS DOCENTES DA UFSC.

(FLORIANOPOLIS, AGOSTO DE 1986).

\begin{tabular}{|c|c|c|}
\hline \multirow[b]{2}{*}{ Pontos Fortes } & \multicolumn{2}{|c|}{ Freqüûência } \\
\hline & $\mathbf{N e}$ & $\%$ \\
\hline Uma ou mais fases do processo & 10 & 35,7 \\
\hline Todo processo & 02 & 7,2 \\
\hline $\begin{array}{l}\text { Levantamento das necessidades humanas } \\
\text { básicas e dos problemas }\end{array}$ & 05 & 17,8 \\
\hline $\begin{array}{l}\text { O método científico que fundamenta } \\
\text { o processo }\end{array}$ & 04 & 14,3 \\
\hline Adaptabilidade do processo & 02 & 7,2 \\
\hline Tot a 1 & 28 & 100,0 \\
\hline
\end{tabular}

Se, por um lado, os docentes reconhecem pontos fortes na teoria $e$ processo de Horta, por outro, sugerem aspectos que deveriam ser melhor definidos e elaborados. Dos 49 professores, 21 (42,9\%) citaram aspectos relacionados com a teoria, expressos na tabela 4 , e $24(49,0 \%)$ aspectos referentes ao processo, expressos na tabela 5 .

Como se observa, a maioria reclama por uma melhor definição e elaboração dos conceitos envolvidos na teoria. Quanto aos aspectos referentes ao processo de enfermagem, as fases mais citadas por melhor definição e elaboração são em primeiro lugar "diagnóstico" e em segun. do "prognóstico". Estes dados eram de se esperar, pois a própria autora reconhecia e declarava em seus escritos, serem as fases de difícil operacionalização. $\mathrm{Na}$ tentativa de refinar o instrumento para a determi. 
ASPECTOS DA TEORIA DE HORTA QUE, NA OPINLAO DOS PROFESSORES

ENFERMEIROS DA UFSC, PRECISAM SER MELHOR DEFINIDOS

E ELABORADOS. (FLORIANOPOLIS, AGOSTO, 1986).

\begin{tabular}{|c|c|c|}
\hline \multirow[b]{2}{*}{ Aspectos Focalizados } & \multicolumn{2}{|c|}{ Frequiência } \\
\hline & $\mathbf{N}^{\circ}$ & $\%$ \\
\hline $\begin{array}{l}\text { Conceitos (necessidade, problema, } \\
\text { enfermagem, funçôes do enfermeiro) }\end{array}$ & 14 & 66,7 \\
\hline Estrutura da teoria & 02 & 9,6 \\
\hline Marco conceitual & 02 & 9,6 \\
\hline Base filos $\delta$ fica & 01 & 4,7 \\
\hline Testagem da teoria & 01 & 4,7 \\
\hline Principios da teoria & 01 & 4,7 \\
\hline Total & 21 & 100,0 \\
\hline
\end{tabular}

TABELA 5

ASPECTOS DO PROCESSO DE HORTA QUE PRECTSAM SER MELHOR DEFINIDOS E ELAABORADOS, SEGUNDO O DEPOIMENTO DOS ENFERMEIROS DOCENTES DA UFSC. (FLORIANOPOLIS, AGOSTO, 1986).

\begin{tabular}{|c|c|c|}
\hline \multirow[b]{2}{*}{ Aspectos Focalizados } & \multicolumn{2}{|c|}{ Frequilencia } \\
\hline & $\mathbf{N e}$ & $\%$ \\
\hline Diagnóstico & 06 & 25,0 \\
\hline Diagnóstico e prognóstico & 08 & 33,2 \\
\hline Diagnóstico, prognóstico e evolução & 02 & 8,4 \\
\hline $\begin{array}{l}\text { Diagnóstico, prognóstico e plano } \\
\text { assistencial }\end{array}$ & 01 & 4,2 \\
\hline Diagnóstico e plano assistencial & 01 & 4,2 \\
\hline Histórico & 01 & 4,2 \\
\hline Histórico e prognóstico & 01 & 4,2 \\
\hline Histórico e plano assistencial & 01 & 4,2 \\
\hline Plano assistencial & 01 & 4,2 \\
\hline Outras respostas & 02 & 8,4 \\
\hline Total & 24 & 100,0 \\
\hline
\end{tabular}

nação do diagnóstico, a autora chegou a propor três modelos sem ter, na época, satisfeito os enfermeiros para sua utilização prática.

Em fevereiro de 1979, realizou-se no Departamento de Enfermagem UFSC, um seminário sobre a "Teoria e prática do Processo de Enfermagem", para o qual se colheu, em janeiro de 1979, a opinião do corpo docente da UFSC, num total de 32 elementos. Os questionamentos levantados na época sobre o ensino, foram repetidos em agosto de 1986, para se poder comparar a opinião atual do corpo docente da UFSC relacionada ao assunto. Os resultados obtidos estão apresentados nas tabelas 6 e 7 . 


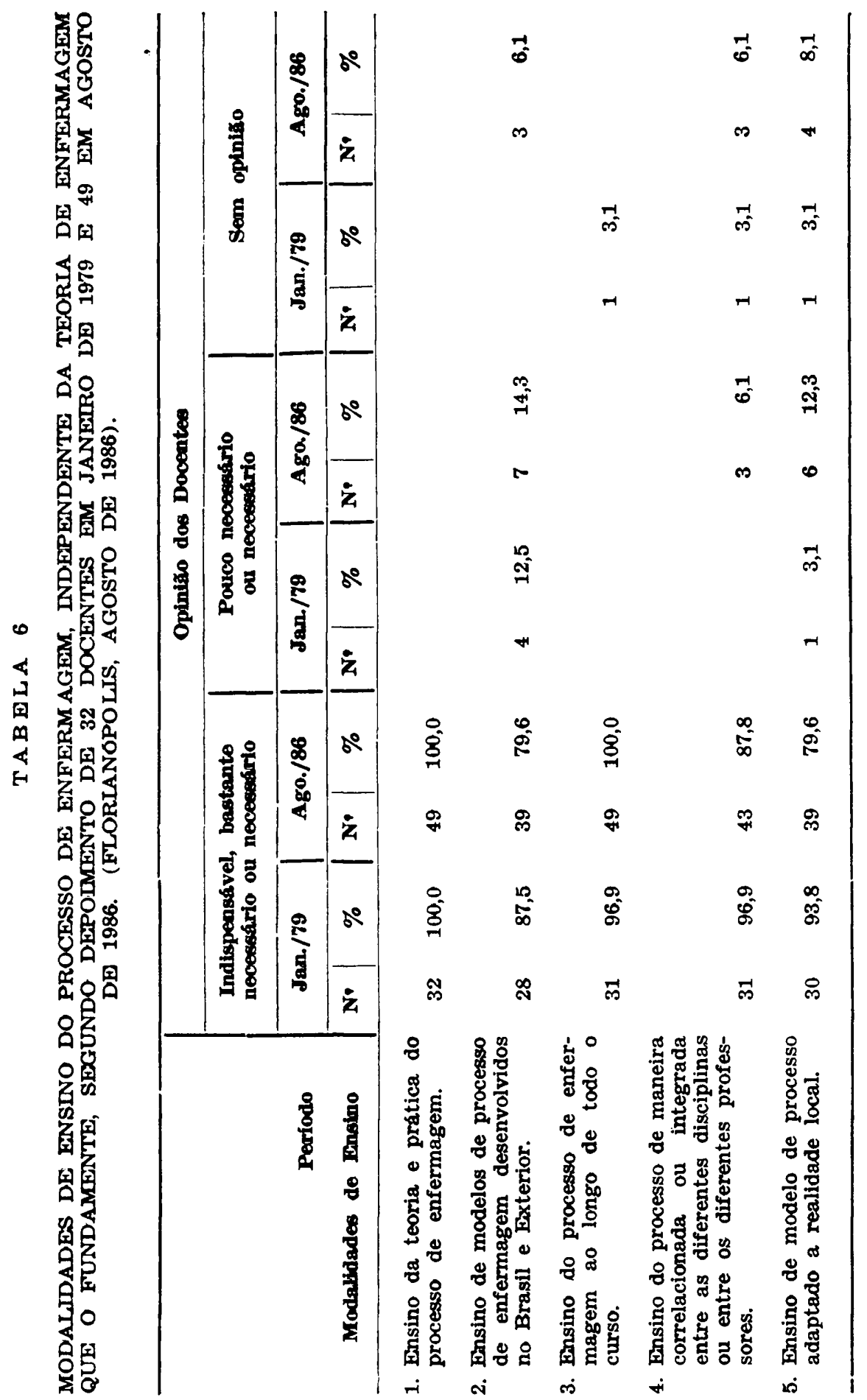




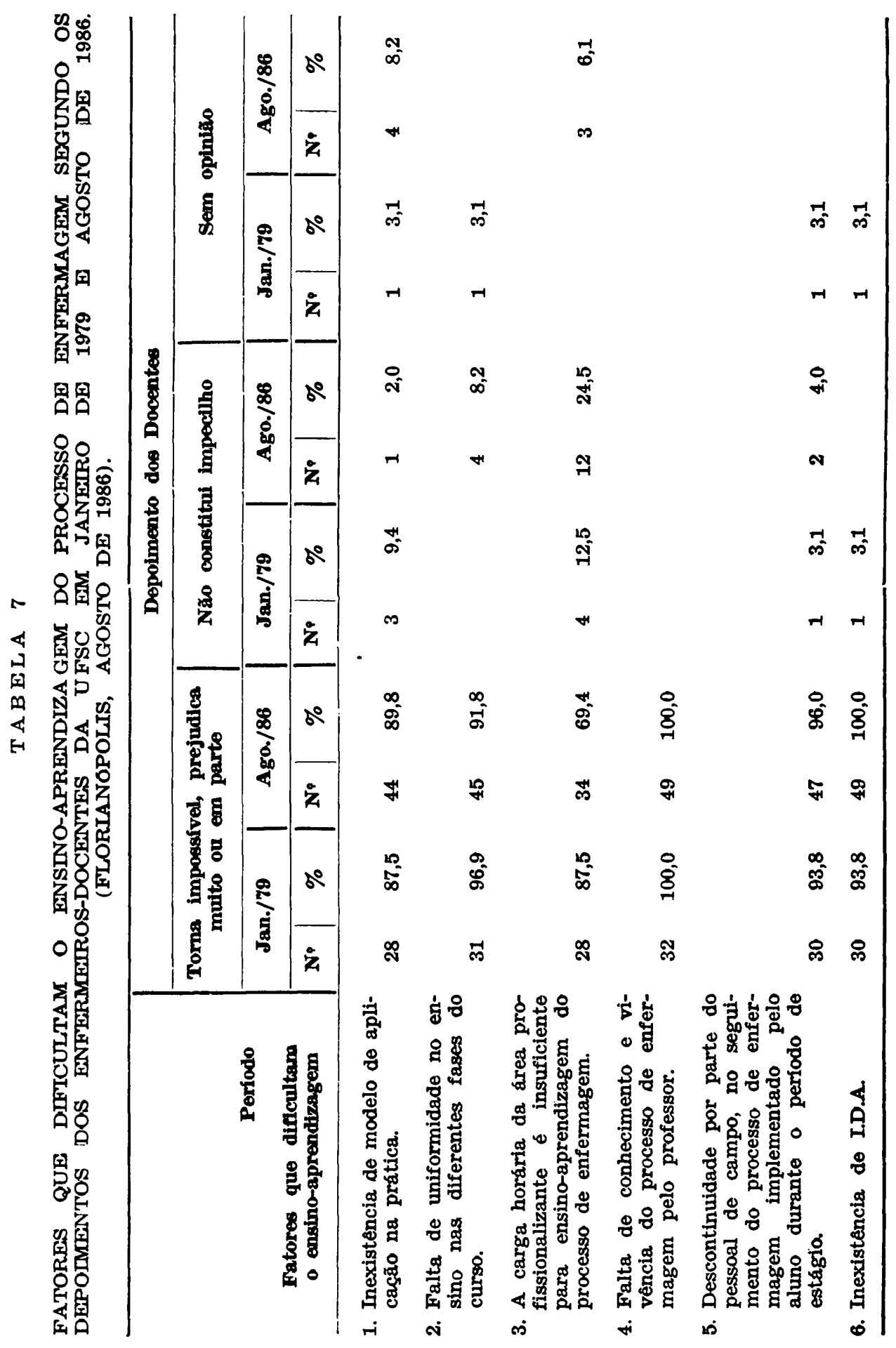

Rev. Esc. Enf. USP, São Paulo, 21 (no especial) :40-54, Jun. 1987. 
Cabe aqui ressaltar que em 1979, a teoria das necessidades humanas básicas e o processo de enfermagem de Horta era, praticamente, a única metodologia conhecida e ensinada pelo corpo docente. Teoricamente, houve um avanço decisivo, até a presente data, em termos de conhecimento das teorias dos principais autores de enfermagem pelo corpo docente da UFSC. Esta mudança foi provocada, inicialmente, pela própria Wanda de Aguiar Horta ao ministrar disciplinas no curso de mestrado em enfermagem na UFSC e, posteriormente, na continuidade do ensino formal, principalmente de pós-graduação, onde as teorias são discutidas e analisadas em maior profundidade.

É surpreendente, como a opinião dos docentes (32) em janeiro de 1979 se aproxima da dos (49) de agosto de 1986 (Tabela 6). A maioria, em alguns itens até $100 \%$, consideram "indispensável", "bastante necessário" ou "necessário" o ensino do processo de enfermagem.

Existe significativa convergência de opiniōes do corpo docente (janeiro/79 e agosto/86) quanto aos fatores que dificultam o ensino e aprendizagem do processo de enfermagem, como se pode observar na tabela 7 . A maioria dos docentes, dos dois periodos citados, afirmaram que a existência dos fatores listados na tabela 7, "torma impossivel", "prejudica muito" ou ainda "prejudica em parte", o ensino aprendizagem do processo de enfermagem.

Em 1979, o curso de graduação em enfermagem da UFSC era constituído por 7 semestres curriculares e atualmente por 8 . Mesmo assim, ainda, 34 docentes $(69,4 \%)$ consideram que a carga horária da área profissionalizante é insuficiente para o ensino/aprendizagem do processo de enfermagem.

Os dados apresentados revelaram que Horta é a teorista mais indicada e utilizada no ensino de graduação em enfermagem na UFSC. Qua] será o comportamento dos egressos frente a estes ensinamentos?

\section{2 - Resultados referentes aos enfermeiros}

Dos 53 enfermeiros lotados na Sub-Diretoria de Enfermagem do Hospital Universitário da UFSC, 45 encontravam-se em atividade no periodo em que o questionário estava sendo aplicado. Destes, $43(95,5 \%)$ devolveram o instrumento em tempo hábil.

Dos respondentes, $39(90,7 \%)$ aprenderam o método de assistência durante o curso de graduação o que sugere uma íntima relação entre o ensino e aprendizagem, pois $86,7 \%$ dos enfermeiros são egressos da UFSC e $73,5 \%$ do corpo docente acredita ser a teoria de Horta a mais adequada para orientar o ensino de graduação em enfermagem na UFSC.

Uma pequena percentagem $(6,9 \%)$ dos enfermeiros referiu não ter recebido orientação sobre a aplicação do método de assistência de enfermagem ao ser admitido no Hospital Universitário. Embora se esperasse que $100 \%$ dos enfermeiros tivessem sido orientados, infelizmente, 
constatou-se que os recém-admitidos não receberam e năo buscaram a devida orientacão.

$\mathrm{Na}$ opinião de $37(86,1 \%)$ enfermeiros, a qualidade de assistência melhora muito com a utilização da teoria das necessidades humanas básicas e processo de enfermagem e $05(11,6 \%)$ são de opinião que a mesma melhora apenas razoavelmente. Vários comentários e depoimentos foram registrados pelos enfermeiros para explicar ou justificar a sua posição como: a qualidade da assistência melhora porque sistematiza-a; prioriza as ações; facilita a avaliação do resultado; facilita o direcionamento e supervisão da assistência; melhora a organização dos cuidados, etc. Alguns depoimentos apontam a falta de pessoal e material como entraves para a aplicação adequada do método e outros, ainda, afirmam que a qualidade da assistência melhora quando a metodologia é encarada com a devida seriedade.

Dos 49 enfermeiros, $32(74,4 \%$ c $)$ declararam que a utilização do método de assistência facilita muito o levantamento de problemas que afetam as necessidades dos pacientes, enquanto $10(23,3 \%)$ acreditam ser razoavelmente facilitada. Os enfermeiros reforçaram suas posições, argumentando que através da utilização de uma metodologia, a assistência é agilizada e facilitada, os problemas do paciente são mais rapidamente e facilmente detectados, facilita o entrosamento da equipe frente às necessidades do paciente, etc. Foi, também, lembrado que o enfermeiro deve ter conhecimento científico e capacidade de observação.

Foi questionado se "o tempo gasto para aplicar a metodologia de enfermagem seria melhor utilizado em cuidados diretos ao paciente". Vinte e sete $(62,8 \%)$ não concordaram com a colocação, $06(14,0 \%)$ posicionaram-se favoravelmente e $10(23,2 \%)$ não se manifestaram.

Várias considerações feitas a respeito da questão são semelhantes às anteriormente colocadas; outras reforçam suas posições tomadas ao assinalar "sim", "não" ou deixar a resposta em branco. A falta de funcionários foi bastante enfatizada, levando, segundo opiniōes, os enfermeiros a prestar cuidados diretos em detrimento do planejamento da assistência. Por outro lado, vários enfermeiros consideram que o método de assistência inclui a prestação de cuidados diretos. Afirmam tam. bém, que o tempo dispendido é bem empregado, na medida em que con. tribui para a melhoria do atendimento direto.

Duas questões semelhante foram colocadas para as quais se esperava respostas não contraditórias: $1^{\text {" }}$ "Os enfermeiros devem lutar para manter a aplicaçấo da metodologia da assistência de enfermagem como função "privativa" dos mesmos?" e $2^{\text {a }}$ "A aplicação da metodologia de assistência de enfermagem pode ser delegada a outros elementos da equipe de enfermagem?". Dos 43 respondentes, 32 (74,4\%) mantiveram coerência nas suas opiniōes, argumentando que só o enfermeiro tem preparo técnico-científico para desempenhar a referida função. Os depoimentos dos onze restantes não se ajustam plenamente à luta histórica brasileira de que a aplicação da metodologia de assistência deva ser 
função "privativa" do enfermeiro, o que parece demonstrar que os mesmos não estão suficientemente esclarecidos quanto ao assunto.

Os passos do método da assistência de enfermagem foram classificados como função assistencial por $38(88,5 \%)$ dos enfermeiros. As demais classificações foram: administrativa $(2,3 \%)$; social $(2,3 \%)$; assistencial, administrativa e social $(2,3 \%)$; assistencial e administrativa $2,3 \%$ ).

O Hospital Universitário da UFSC utiliza, atualmente, 3 passos do processo de enfermagem de Horta, considerados indispensáveis por 40 $(93,4 \%)$ dos respondentes, sendo que $07(16,3 \%)$ incluiriam o plano inicial (assistencial), excluído em outubro de 1984 e 28 (65,1\%) não são favoráveis à inclusão de nenhum dos demais passos do hexágono de Horta.

As maiores dificuldades que os enfermeiros encontram na aplicação das fases do processo de enfermagem estão relacionadas com a evolução - $17(39,5 \%)$ e, com o histórico - $09(21,0 \%)$. Seis $(14,0 \%)$ não encontram dificuldade com relação a nenhum dos passos. A elaboração da evolução de enfermagem segue as orientações de WEED (14) que sugere a organização dos dados em subjetivos, objetivos, análise ou avaliação e planos. Os enfermeiros consideram a evolução mais difícil, porque, segundo eles, exige: profundo conhecimento técnico-científico, raciocínio e constante atualização da fisiopatologia. O tempo disponível para elaborar uma evolução adequada é bastante questionado pelos enfermeiros, pois constantemente, deparam-se com a falta de pessoal. Possivelmente, os enfermeiros que têm a prática habitual de complementar suas deficiências através de estudo individual sistemático, possuem mais facilidade para elaborar a evolução.

A análise dos resultados, referentes a opinião dos enfermeiros quanto a teoria e processo de enfermagem mais adequada a nossa realidade, foi prejudicada pelo alto percentual $(58,2 \%)$ obtido da soma entre os que não responderam, acrescida daqueles que não optaram por Horta, declarando que sua posição devia-se ao desconhecimento das demais teorias. Todavia, $16(37,2 \%)$ enfermeiros apresentaram uma posição definida por Horta.

Os enfermeiros foram convidados, também, a classificar o seu "nível de conhecimento em relação às principais teorias e processo de enfermagem" e o seu "nivel de prática na utilização" das mesmas, cujo resultado pode ser apreciado na tabela 8.

Considerando que o método de assistência de enfermagem do Hospital Universitário fundamenta-se na teoria das necessidades humanas básicas preconizada por Horta, considerando também que 86,7\% dos enfermeiros da Instituição são ex-alunos do curso de graduação da UFSC, cujo corpo docente acredita ser a teoria de Horta a mais adequada $(73,5 \%)$ e a mais utilizada $(69,4 \%)$ no ensino, parece evidente que os 


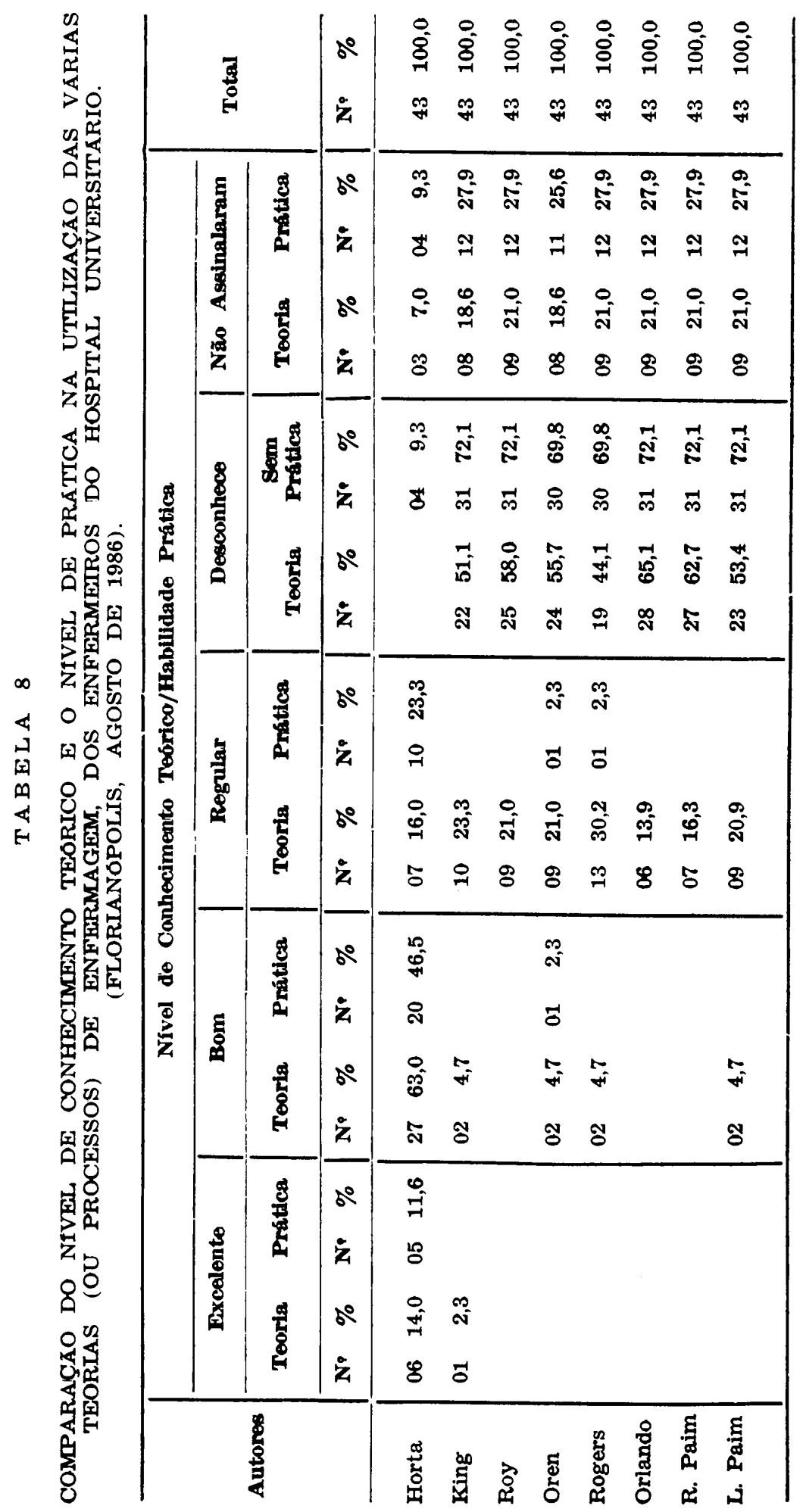


enfermeiros devessem ter maior conhecimento, tanto a nivel teórico como na prática, da teoria das necessidades humanas básicas.

Todavia, a existência de enfermeiros recém-admitidos na instituição e a não utilização do método de assistência em determinadas áreas do ambulatório, podem justificar a classificação "regular" e "sem prática" em relação à teoria de Horta (tabela 8).

O desconhecimento dos enfermeiros no que se refere à maioria das teorias ficou caracterizada na tabela 8 , representado tanto pelos que não assinalaram como pelos que declararam o seu desconhecimento.

\section{5 - Considerações Finais}

Os resultados do presente estudo, levam-nos a considerar que Horta continua influenciando o ensino e a prática dos enfermeiros da UFSC, o que ficou evidenciado pela preferência dos docentes pela teoria e processo de enfermagem da autora no ensino e, pela sua utilização, pelos enfermeiros, na prática, no Hospital Universitário.

Caso novos estudos sejam efetivados, visando testar e aprimorar a teoria, bem como operacionalizar mais adequadamente o processo, mormente nas fases que apresenta uma significativa deficiência, acreditamos que muitas gerações de enfermeiros ainda utilizarão esta metodologia no seu ensino, prática ou investigação, bem como muitos indivíduos, famílias ou grupos receberão assistência de enfermagem orientada para $o$ atendimento de suas necessidades básicas.

The purposes of the present study were to: a) assess the nurses opinions and cxperience (about) with Horta's theory and nursing process, and b) compare the current faculty's opinions about nursing process teaching with the faculty's opimions gathered in 1979. The sample consisted of 49 nursing faculty members and 43 nurses who worked at an hospitat. The data were collected through a questionnaire. The findings showed that the Theory of Basic Human Needs proposed by Horta was the model most used in the nursing education and practice settings at the Federal University of Santa Catarina.

\section{6 - Bibliografia}

1. CASTEllanos, B.E.P.; SALZANO, S.D.T.; JOUClaS, V.M.G. Planejamento do cuidadu de enfermagem ao paciente durante o periodo transoperatório: ensino do estudante de enfermagem - I. Rev. Esc. Enf. USP, São Paulo, 12(3):150-55, 1978.

2. CIANCIARUllo, T.I.; KOIZUMt, M.S.; FERNANDES, R.A. Prescrição de enfermagem. Experiências de sua aplicação $\mathrm{em}$ hospital particular. Rev. Bras. Enf., Brasilia, 27(2):144-49, abril, jun. 1974 .

3. ENFERMAGEM em Novas Dimenszes. Volumes 01 a 05 , publicados de 1975 a 1979.

4. NOGUEIRA, M.J.C. et alii. Um modelo de histórico e plano de assistência de enfermagem à família. Rev. Esc. Enf. USP, Sđ̃o Paulo, 12(1):17-60, 1970.

5. SAUPE, R. \& HORR, L. Sistemática de asistência de enfermagem no Hospital Universitário da UFSC. Rev. Cien. Saúde, Florianópolis, 1(2):9-20, dez. 1982.

6. WALDOW, V.R. Relato de experiência de ensino da disciplina Assistência de Enfermagem ao Adulto I na zona rural. Rev. Gaúcha Enf., Porto Alegre, 6(1):63-82, jan., 1985. 